\title{
Spontaneous rupture of splenic artery aneurysm in pregnancy: an autopsy-based case report
}

\author{
Aditya Anand*, Mohit Gupta, Manish Kumath, Sanjay Kumar
}

Department of Forensic Medicine, VMMC and Safdarjung Hospital, New Delhi, India

Received: 12 January 2021

Accepted: 11 February 2021

\section{*Correspondence:}

Dr. Aditya Anand,

E-mail: adityasmc2012@gmail.com

Copyright: (c) the author(s), publisher and licensee Medip Academy. This is an open-access article distributed under the terms of the Creative Commons Attribution Non-Commercial License, which permits unrestricted non-commercial use, distribution, and reproduction in any medium, provided the original work is properly cited.

\begin{abstract}
Splenic artery aneurysm (SAA) is an infrequent form of vascular disease that has a significant potential for rupture, resulting in life-threatening intraperitoneal hemorrhage commonly during pregnancy. The incidence of splenic artery aneurysms has been estimated between $0.01 \%$ and $0.98 \%$. We describe a case of sudden death of a 36 years old full term, primigravida female. During autopsy we found ruptured splenic artery aneurysm about $2.0 \mathrm{~cm}$ in diameter near hilum with intraperitoneal hemorrhage. It is important to be alert about the possibility of SAA in pregnant women for its early diagnosis, as the chance of it getting ruptured during pregnancy is high with high maternal and fetal mortality rates.
\end{abstract}

Keywords: Splenic artery, Autopsy, Rupture, Pregnancy, Aneurysm and intraperitoneal hemorrhage

\section{INTRODUCTION}

Splenic artery aneurysm (SAA) is an infrequent form of vascular disease and has a significant potential for rupture and life threatening hemorrhage. Complications may occur in $10 \%$ of all cases with a mortality rate of $10-25 \%$ in nonpregnant patient and up to $70 \%$ during pregnancy. It presents as sudden, unexpected deaths to be diagnosed mostly at the time of autopsy. ${ }^{1,2}$ Aneurysm is the thinning and dilatation of vascular wall. It can be true or pseudo aneurysm. In a true aneurysm all layers of vessel wall are intact while in a pseudoaneurysm there is tear in vascular wall leading to perivascular hematoma with no associated thinning or dilatation. ${ }^{1,3}$ The causes of true SAA are not well known, however, atherosclerosis and congenital defects of the arterial wall have been described as the major causes. Acute and chronic pancreatitis are thought to be the major causes of pseudo aneurysm. ${ }^{3}$

Splenic artery aneurysm has high risk of rupture, mostly during third trimester, due to the metabolic and hormonal changes occurring in pregnancy. ${ }^{4-6} \mathrm{We}$ are reporting one such case of splenic artery aneurysm rupture in a pregnant female leading to sudden unexpected death.

\section{CASE REPORT}

A 36 years old, primigravida, full term female weighing 80 kgs was brought to the emergency department of a tertiary care hospital with history of two episodes of vomiting while relaxing in a chair and watching television. She was declared brought dead and body was sent to mortuary for medicolegal autopsy. She had past history of hypertension and diabetes. On external examination no ante-mortem external injury was present. Conjunctiva of both eyes was pale. On internal examination, abdominal cavity contained about $2.0 \mathrm{~kg}$ of clotted blood and about one litre of liquid blood as shown in Figure 1. On further dissection and retracting the stomach and pancreas, blood clots were seen in the area of splenic hilum as shown in Figure 2 and 3. On removal of blood clots, ruptured splenic artery aneurism about $2.0 \mathrm{~cm}$ in diameter was seen near hilum. Weight of spleen was 335 gms. All other organs were pale. Cause of death was opined hemorrhagic shock consequent to spontaneous rupture of splenic artery aneurysm. 


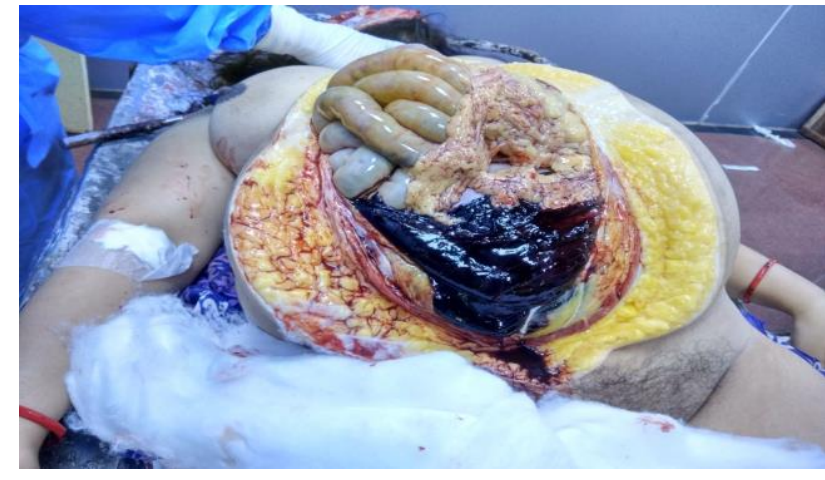

Figure 1: Abdominal cavity showing blood clot.

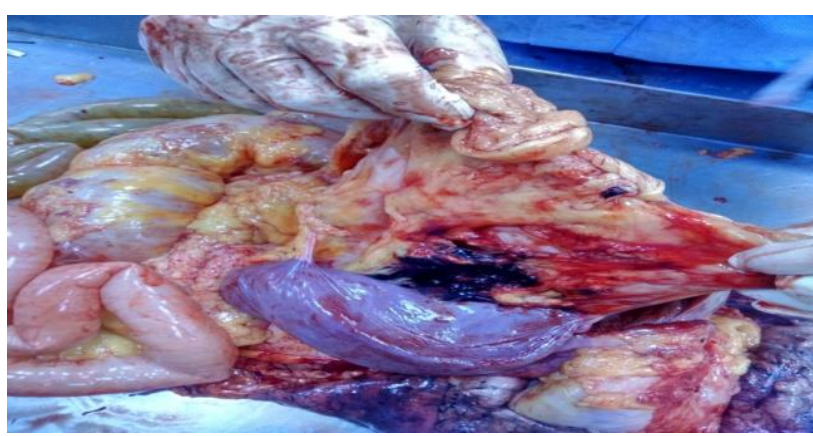

Figure 2: Blood clot in the area of splenic hilum on retracting the stomach and pancreas.

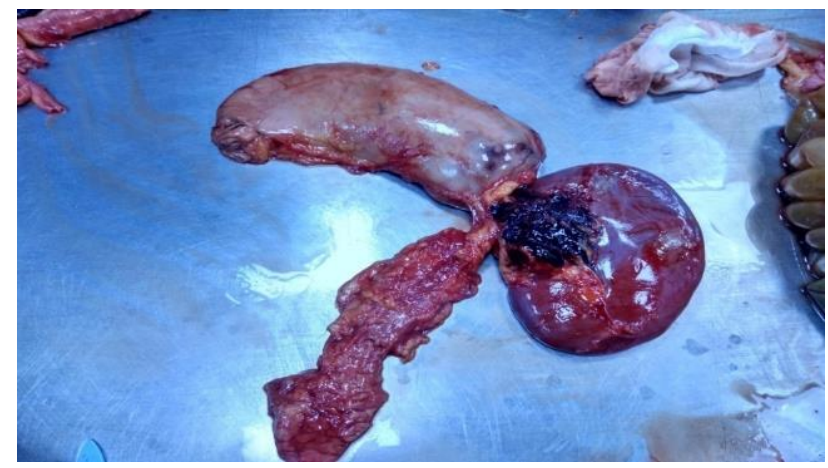

Figure 3: Spleen, stomach, pancreas and blood clot and ruptured splenic artery aneurism at splenic hilum.

\section{DISCUSSION}

SAA has an estimated prevalence of $0.01 \%$ and $0.98 \% .^{7}$ After aortic and iliac artery aneurysm, SAA is the third most common intra-abdominal arterial aneurysm. It accounts for about $60 \%$ of all splanchnic arterial aneurysm. ${ }^{8,9}$ Once ruptured it has a mortality rate of 10 $25 \%$ in non-pregnant individuals, which increases to $70 \%$ during pregnancy and is associated with fetus mortality rate of $95 \% .{ }^{1,2,9}$ About $65 \%$ of all SAA are present in pregnant women of which 20-50\% may rupture. Most commonly this occurs during third trimester $(69 \%)$, at child birth (13\%), during first two trimesters (12\%), $13 \%$ and at puerperium $(6 \%){ }^{9-12}$
Although the pathogenesis of the condition is obscure, during pregnancy there are many hormonal changes like increase in circulating hormones like estrogen, progesterone, relaxin and metabolic changes leading to increase in blood volume and heart rate, which ultimately leads to raised blood pressure. All these changes along with an enlarged uterus compressing the iliac artery and aorta, increases blood flow within splenic artery leading to SAA.

Many risk factors have been associated with SAA rupture like systemic hypertension, portal congestion, liver diseases, multiple pregnancies and size of aneurysm. SAA of size more than $2 \mathrm{~cm}$ in diameter is more prone to rupture. ${ }^{9,12,13}$ In our case, though the female was primigravida, the other risk factors like hypertension, obesity and aneurysm size of $2 \mathrm{~cm}$ may have contributed in the rupture of aneurysm.

SAA are generally asymptomatic and the diagnosis of unruptured aneurysm during pregnancy is very difficult. As a result the initial recognition and diagnosis of SAA take place only after they have ruptured or at autopsy. A phenomenon known as "double rupture" is reported in $25 \%$ of cases where the bleeding remains confined to the lesser sac initially for around 6-96 hours which may cause pain and transient hypotension, followed by free intraperitoneal hemorrhage and collapse of the patient. This time period between initial hemorrhage in lesser sac and free intraperitoneal hemorrhage provides an opportunity to diagnose the aneurysm and intervene. ${ }^{9,12}$ As in the present case the patient with ruptured SAA presents with symptoms of nausea, vomiting, hypotension, these are similar to other more common obstetrical emergencies like uterine rupture leading to misdiagnosis of the condition in about $70 \%$ of cases. Hence, pregnant women who are experiencing pain in the left upper part of abdomen or in hypovolemic shock with complain of nausea, vomiting and no other findings at obstetric examination should be screened immediately for possible SAA. ${ }^{12-14}$

\section{CONCLUSION}

Even though SAA is a rare condition in pregnancy, its rupture poses a very high risk of maternal and fetal mortality. It is important to be aware about SAA and its complications, for early diagnosis and timely management, to increase the chances of maternal and fetal survival. The case highlights that routine screening for SAA should be done in all pregnant women including primigravida and special attention should be given to females with risk factors.

\section{ACKNOWLEDGMENTS}

Authors would like to thank Dr. Nagendra Singh Sonwani, Department of Forensic Medicine, University college of Medical Sciences and Guru Teg Bahadur Hospital, New 
Delhi and the mortuary staff of VMMC and Safdarjung Hospital, New Delhi.

Funding: No funding sources Conflict of interest: None declared

Ethical approval: Not required

\section{REFERENCES}

1. Abdulrahman A, Shabkah A, Hassanain M, Aljiffry M. Ruptured spontaneous splenic artery aneurysm: a case report. Int J Surg. 2014;5:754-7.

2. Manian U, Badri H, Coyne P, Nice C, Ashour H, Bhattacharya V. Endovascular treatment of a ruptured splenic artery aneurysm using amplatzer ((R)) vascular plug. Int J Biomed Sci. 2009;5(1):81-4.

3. Cordova AC, Sumpio BE. Visceral artery aneurysms and pseudoaneurysms-should they all be managed by endovascular techniques? Ann Vasc Dis. 2013;6(4):687-93.

4. Sadat U, Dar O, Walsh S, Varty K. Splenic artery aneurysms in pregnancy-a systematic review. Int $\mathbf{J}$ Surg. 2008;6(3):261-5.

5. Al-Habbal Y, Christophi C, Muralidharan V. Aneurysms of the splenic artery-a review. Surgeon. 2010;8:223-31.

6. Gourgiotis S, Alfaras P, Salemis NS. Spontaneous rupture of splenic artery aneurysm in pregnancy: a case report. Adv Med Sci. 2008;53(2):341-3.

7. Tsokos M, Nolting RO, Lockemann U. Sudden, unexpected death due to splenic artery aneurysm rupture. Am J Forensic Med Pathol. 2005;26(1):83-5.
8. Katirci Y, Karamercan MA, Ramadan H, Baran NT, Aksoy O, Coskun F. Spontaneous ruptured splenic artery aneurysm: a case report. Hong Kong J Emerg. Med. 2013;20(4):248-5.

9. Dhinakar M, Mashini SA, Golash V. Rupture of splenic artery aneurysm during pregnancy: a report of two cases. Oman Med J. 2011;26(5):99-101.

10. Holdsworth RJ, Gunn A. Ruptured splenic artery aneurysm in pregnancy. A review. $\mathrm{Br} \mathrm{J}$ Obstet Gynaecol. 1992;99(7):595-7.

11. O'Grady JP, Day EJ, Toole AL, Paust JC. Splenic artery aneurysm rupture in pregnancy. A review and case report. Obstet Gynecol. 1977;50(5):627-30.

12. He M, Zheng J, Zhang S, Wang J, Liu W, Zhu M. Rupture of splenic artery aneurysm in pregnancy a review of the literature and report of two cases. Am J Forensic Med Pathol. 2010;31(1):92-4.

13. Parrish J, Maxwell c, Beecroft JR, Splenic artery aneurysm in pregnancy. J Obstet Gynaecol Can. 2015;37(9):816-8.

14. Barrett JM, Van Hooydonk JE, Boehm FH. Pregnancy related rupture of arterial aneurysms. Obstet Gynecol Surv. 1982;37:557-66.

Cite this article as: Anand A, Gupta M, Kumath M, Kumar S. Spontaneous rupture of splenic artery aneurysm in pregnancy: an autopsy-based case report. Int J Reprod Contracept Obstet Gynecol 2021;10:1739-41. 